\title{
Tras las huellas \\ de una Eva prometeica
}

Isabel Cabrera

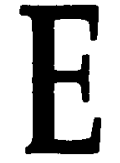

$s$ generalmente reconocido que la misoginia bíblica comienza con Eva, quien no sólo es creada para acompañar a Adán, a partir de su costilla, sino además lo induce a pecar y a ser expulsado del paraíso. Eva resulta ser un apéndice nocivo, nació para ser subordinada y, sin embargo, pervierte a su señor: tal vez porque es débil frente a la tentación, tal vez porque es tonta y no mide las consecuencias, tal vez porque es intrinsecamente mala.

El mito al que estamos haciendo alusión no es, sin embargo, el único mito judeo-cristiano acerca del origen del género humano. Antes en el Génesis -aunque no antes en el tiempo- se dice que en el quinto día, los dioses decidieron crear al ser humano, "macho y hembra" a "imagen suya". Tras crearlos se les bendijo y se les pidió que se reprodujeran, y poblaran y dominaran la Tierra. ${ }^{1}$ Este primer relato procede -de acuerdo a la Biblia de Jerusalén-2 del documento sacerdotal, responsable de la actual unidad del Génesis y probablemente escrito en el siglo vi a. C. El siguiente relato, que irrumpe en 2:4 y llega hasta 3:24, y que es el que nos interesa, procede en cambio de un documento más antiguo, llamado yahvista, que se calcula que fue redactado en el siglo IX a. C. en Judá. No obstante la introducción del relato posterior, la historia de Eva y la serpiente, es la que más presencia ha conseguido en nuestra mitología colectiva.

El Génesis es uno de los textos más analizados de Occidente y no quisiera aquí, ni emular una erudición que no poseo, ni perderme entre las diversas y complejas interpretaciones; sólo quiero seguir los rastros de una lectura subterránea, en parte similar a la que sugiere Ernst Bloch, y que me interesa por dos razones: la primera es que revierte por completo la interpretación

' Génesis, 1:24-30, en Biblia de Jerusalén.

${ }^{2} C f$. Introd. y comentarios a Génesis, 1:1 y 2:4, en op. cit. 
tradicional, al dar a Eva un papel privilegiado y positivo en la escena -cuestión que pretendo dejar clara aquí; y en segundo lugar, porque ilumina de manera especial textos bíblicos posteriores que he analizado en otra partey a los que ya no aludiré aquí. Como se verá, esta lectura está montada sobre otras interpretaciones y supone una concepción abierta del texto: el Génesis no esconde una verdad única, sino cuenta historias cuyo valor está en su capacidad de volverse recreaciones parciales de nuestra propia historia que, independientemente de las intenciones originales de los autores, puedan iluminar nuestro presente. Intentemos mezclar voces para volvernos a contar la misma vieja historia, aunque de otra manera.

La idea es leer el pasaje de la expulsión del paraíso de una manera obvia, tomando textualmente la expresión "el árbol de la ciencia del bien y del mal", y asumiendo una perspectiva moral heredada de Kant: si el pecado de Eva es comer de este árbol, el pecado de Eva será su decisión de adquirir el conocimiento moral, la ciencia del bien y del mal, y lo que ello implique. Pero este hecho y sus posibles consecuencias no son -vistos desde nuestros ojos ilustrados- una pérdida sino, al contrario, una ganancia: la lejanía de Dios vale la pena si con ella se consigue la autonomía moral, la capacidad de guiarse por el propio juicio y no por un principio de autoridad. Eva es, en realidad, un personaje prometeico. Pero vayamos paso a paso.

De acuerdo con esta sección del Génesis, el Todopoderoso creó a Adán y lo puso en un jardín lleno de árboles para que lo guardase y cuidase, y también para que se alimentara de él. Hecho esto, Yavé se dirige a Adán por primera vez y emite una única prohibición: "no comer del árbol de la ciencia del bien y del mal". La prohibición de Yavé está acompañada de una amenaza: si comes, "morirás sin remedio". Después se le concede a Adán el poder de nombrar otras criaturas, y por último, Yavé, compasivo de su soledad, toma una de sus costillas y le hace una compañera: Eva es creada.

La prohibición emitida por Yavé es muy sugerente para nuestros propósitos: al prohibir comer de este árbol, Yavé pretende evitar que el ser humano adquiera el conocimiento moral y con él, la capacidad de autolegislarse. En términos kantianos, diríamos que Adán y Eva están condenados, a pesar de los privilegios del primero, a vivir de forma heterónoma, guiados por una voluntad externa, y no por sus propias consideraciones y reflexiones morales. Yavé es quien señala la frontera entre lo permitido y lo prohibido, es el parámetro de conducta. Lo bueno es lo que Yavé permite, lo malo, lo que Yavé prohíbe.

Más tarde aparece en la escena una serpiente que tienta a Eva, y lo hace dando razones: no es seguro que morirán y, en cambio, sí es seguro que "se harán como dioses", conocedores del bien y del mal. La secuencia es coherente con la lectura que iniciamos atrás: al no poseer el conocimiento 
moral, las criaturas se guían por el placer y el temor, es decir, se guían -volviendo a la terminología kantiana- por meros imperativos hipotéticos, reglas de la forma: "debo hacer $X$ porque su consecuencia es placentera", $o$ "no debo hacer $Y$ porque su consecuencia es dolorosa". En este sentido, Yavé da un imperativo hipotético: "no deben comer porque morirán" y la serpiente le opone otro: "deben comer si quieren ser como los dioses" y debilita la amenaza del primero. La serpiente -identificada con Satanás por el posterior cristianismo- se parece mucho -como dice Bloch- a la oruga de la posterior diosa razón. ${ }^{3}$

En este sentido, la alternativa entre comer o no, podría traducirse a la siguiente: continuar en un estado de completa dependencia, orientados por los mandatos del Todopoderoso, o adquirir un conocimiento propio de los dioses, y con él la capacidad de dar y cuestionar órdenes. El pecado original es, más bien, una decisión original: antes de comer, las criaturas no poseen la ciencia del bien y el mal, sino la adquieren con la transgresión. Antes de caer las criaturas no se guían por consideraciones morales sino por la balanza entre placer y dolor, interés y temor. Es la desobediencia a la autoridad de Yavé lo que les brinda la conciencia de su propia libertad, de poder determinar su voluntad con base en consideraciones de otra índole. La desobediencia original es más que la primera falta moral, la condición de posibilidad de cualquier falta. La caída significa, dice Von Rad, el paso de un estado de absoluta dependencia a la adquisición de la autonomía. ${ }^{4}$ Ya una antigua traducción aramea de la Biblia comenta que "de Adán -y debió haber dicho de Eva- surgirá un pueblo que sabrá distinguir entre el bien y el mal". 5 No en balde, en el propio contexto bíblico, el pasaje donde Abraham discute con Yavé la justicia de destruir Sodoma, o los incansables versos de Job que disputa la justicia de su propia suerte. No veo cómo esto no pueda ser una ganancia.

Pero volvamos al texto bíblico. Eva cae, Adán cae y, cuando son descubiertos, el castigo por la transgresión ratifica los vaticinios: ahora que se han hecho como dioses, conocedores del bien y del mal, habrán de ser desterrados del paraíso y enfrentados al sufrimiento y la muerte. ¿Pero cuál es la necesidad de la condena? De acuerdo con nuestra interpretación, la razón es clara: tras haber comido el fruto prohibido, Adán y Eva son capaces no sólo de desobedecer, sino también y sobre todo, de poner en duda las órdenes de

${ }^{3}$ Cf. Ernst Bloch, El ateísmo en el cristianismo. Trad. de J. A. Gimbernat. Madrid, Taurus, 1983, pp. 80-83.

${ }^{4}$ Gerhard von Rad, El libro del Génesis. Trad. de S. Romero. Salamanca, Sigueme, 1988. p. 117.

${ }^{5}$ P. Grelot, Los targumes. Trad. de A. Ortiz Garcia. Navarra, Ed. Verbo Divino, 1987, p. 13 . 
Yavé conforme a su recién adquirido conocimiento del bien y el mal. El hombre es ahora capaz de legislar su destino y en el jardín del Edén no hay espacio para dos legisladores. La conciencia adquirida hace a la criatura -que no es sino barro con aliento divino- rival de su creador.

Hay, sin embargo, otras posibilidades, y el propio texto bíblico sugiere explicitamente una de ellas: Adán y Eva son castigados porque los dioses del Edén -y hablo en plural sólo cuando el Génesis lo hace- temen que, ahora que Adán y Eva son poseedores del conocimiento del bien y del mal, coman del árbol de la vida que es, al parecer, el que realmente importa. Según este mito, al comer el fruto del conocimiento, perdimos el acceso a la inmortalidad. Muchos textos de religiones comparadas insisten en esto: no hay pecado, lo que hay es un engaño, la serpiente miente para alejar al hombre del fruto de la inmortalidad. Como en el mito de Gilgamesh, una serpiente roba la inmortalidad al hombre. ${ }^{6}$ De cualquier manera, esta interpretación es similar, en un sentido importante, a la antes sugerida. En ella los dioses también se sienten amenazados por sus criaturas, que se han convertido en rivales. Después de todo, la serpiente tenía razón, comer los hizo poderosos, y aunque perdieron la inmortalidad, ganaron altura frente a Yavé.

Pero no vayamos tan aprisa, hay otras razones para ver algo negativo en la adquisición de este conocimiento. Así, por ejemplo, Maimónides, ${ }^{7}$ y más tarde Eckhart, ${ }^{8}$ piensan que antes de la transgresión las criaturas fueron creadas, a semejanza de los dioses, capaces de discernir lo verdadero de lo falso y de captar esencias (de ahí el poder de nombrar a los animales); pero con la transgresión y la adquisición del conocimiento del bien y del mal, o sea (y nótese lo forzado de la interpretación), "del conocimiento sensible", su mirada puramente inteligible quedó enturbiada para siempre con los matices y las imprecisiones de la sensibilidad. Al perder el paraíso, fuimos desterrados de la verdadera realidad y estamos condenados a añorarla. En la misma tradición neoplatónica, Eliade comenta que la caída produce un cambio ontológico en la estructura del mundo: a raíz de ella, el hombre está inmerso en una realidad dual y conserva la intuición de que tales opuestos son, en realidad, aspectos complementarios de una realidad única. Para reencontrarse con Dios, la criatura tendrá que trascender el conocimiento del bien y

${ }^{6}$ Cf. Mircea Eliade, Traité d'histoire des religions. París, Payot, 1949, pp. 262-263, y James G. Frazer, El folklore en el Antiguo Testamento. Trad. de Gerardo Novás. Mé. xico, FCE, 1986, pp. 27-32.

${ }^{7}$ Maimónides, Guía de perplejos. Trad. de D. G. Maeso. Madrid, Ed. Nacional, 1984, pp. $72-74$.

${ }^{8}$ Maitre Eckhart, Commentaire de la Génèse. Trad. y ed. de F. Brunner. París, Ed. du Cerf, 1984, pp. 511-517. 
del mal, reconocerlos como ilusorios, y buscar una realidad más allá de los opuestos. ${ }^{9}$

Por otra parte, hay quienes piensan que el pecado original es una pérdida, básicamente porque identifican, equivocadamente y sin razones adicionales, el conocimiento del mal con la tendencia al mal: al desobedecer Eva nos hereda una intrínseca inclinación al mal. Así, por ejemplo, san Agustín cree que la expresión "hacernos como dioses" no es sino una ironía; más bien nos hemos hecho conocedores del mal porque lo sentimos dentro de nosotros mismos. ${ }^{10}$ Un texto posterior de la tradición judía, el Tseenah Ureenah, advierte que pronto el conocimiento del mal se vuelve tendencia al mal. ${ }^{11}$

Sin embargo, lo más común es que el autor reconozca que el conocimiento del bien y del mal no es por sí mismo algo nocivo; y no obstante, piense que sí hay mal en lo que significa querer adquirir este conocimiento. Autores de diversas tradiciones concuerdan en esto: el mal está en la avaricia de querer ser como dioses. San Agustín dice que el fruto en sí no es malo, lo que es malo fue desobedecer: convenía prohibir al hombre algo, para asi hacer resaltar su obediencia y suprimir su orgullo; el pecado es la soberbia, la arrogancia. ${ }^{12}$ Por su parte, el Pirqué de Rabbi Eliézer, un texto muy preciado de la tradición judía, dice que al estar prohibido, el árbol era "como un saco de alacranes"; la falta refleja la ambición de Eva respecto a Dios. ${ }^{13} \mathrm{Tam}$ bién Lutero insiste en que la alternativa entre comer o no, es la alternativa entre el temor a Dios y la incredulidad y la arrogancia. ${ }^{14}$ De esta manera, aunque Adán y Eva aún no hubieran adquirido el conocimiento del bien y del mal, sí eran capaces de obrar mal, guiados por la arrogancia, la ambición o la incredulidad. La interpretación de Lutero es muy elocuente en este último punto: el árbol -dice- es una representación sensible de la obediencia, como tal, Adán y Eva podrian haberlo convertido en un templo frente al cual demostrar su íntima fidelidad. El árbol era bueno, es la prohibición y la

${ }^{9}$ M. Eliade, en W. C. Beane y W. G. Doty, eds., Myths, Rites, Symbols. Nueva York, Harper Books, 1976, pp. 440-443.

"San Agustín, "Del Génesis contra los maniqueos" y "Del Génesis a la letra". Trad. Bilbaíno Martín, t. XV, en Obras completas. Madrid, BAC, 1957, p. 473.

${ }^{11}$ J. B. I. Achkenazi de Janow, Le Commentaire sur la Torah. Tseenah Ureenah. Trad. de J. Baumgarten. París, Verdier, 1987, p. 54.

${ }^{12}$ San Agustín, "Del Génesis contra los maniqueos" y "Del Génesis a la letra", en op. cit., p. 963, y "La ciudad de Dios". Trad. de S. Santamarta y M. Fuentes, en op. cit., t. xvII, p. 20.

${ }^{13}$ Eliézer Rabbi, Pirqué de Rabbi Eliézer. Trad. de M. A Ouaknin y E. Smiliévitch. París, Verdier, 1983, pp. 81 y 84.

${ }^{14}$ Martin Lutero, "Commentaire du Libre de la Genese", en Ouvres, t. XVII. Ginebra, Labor et Fides, 1975, p. 146. 
desobediencia las que lo vuelven nocivo. De hecho, advierte Lutero, podía haberse convertido en el pilar de la religión más depurada y más simple: Yavé pide sólo una cosa: que su criatura le alabe y le dé gracias, no comiendo de aquél árbol, Yavé pide a su criatura la celebración de un único culto. Pero Adán y Eva se dejan tentar por la duda, y retiran su confianza de Dios para depositarla en su razón: "¿por qué no habriamos de comer si los frutos parecen buenos?", la razón intervino para cuestionar, y desplazó a la fe; la incredulidad y la duda que aparecen cuando nos apartamos de la Palabra -dice Lutero- son la fuente de todos los pecados. ${ }^{15}$

Pero estas interpretaciones que remiten el mal al desafio de la autoridad divina, ponen el acento en el "quién ordena" y no en el "por qué ordena"; es decir, no importa qué y por qué prohibió Yavé, importa sólo que es Yavé quien lo prohibió. Pero para una razón ilustrada el "quién" no puede nunca desplazar al "por qué" en cuestiones morales; se pretende justamente no obrar por argumento de autoridad sino por convencimiento racional. Por eso la elección no es, como bien señalan Buber y Panikkar, entre bien y mal sino entre dos principios de autoridad: Dios y la serpiente. ¿Por qué Adán y Eva tendrian que pensar que vivir bajo la tutela de Yavé, como en un capelo, honrando al árbol del conocimiento como si fuera un templo, es lo mejor para ellos? La caída es un mito del inicio de nuestra historia, una metáfora de cómo adquirimos esta capacidad de autogobernarnos.

Recojo brevemente dos interpretaciones de este pasaje hechas por Kant, que parcialmente apoyan la que aquí se sugiere. La primera interpretación está expuesta en su texto "Comienzo presunto de la historia humana", escrito en 1786: según Kant, el comer el fruto prohibido representa la superación del instinto. El ser humano -en alguna etapa de su evolución- estaba dirigido por sus instintos, la voz de Dios representa el instinto que dice al animal humano "no comas esto porque es peligroso, puedes morir". La serpiente, por su parte, representa la voz de la razón que escudriña beneficios y consecuencias más allá de las apariencias. Al desobedecer al instinto, el ser humano descubre que también su razón -y no sólo sus impulsos- puede determinar su voluntad. La caída es un progreso, una liberación: el paso irreversible de la "tutela de la Naturaleza" al "estado de libertad". ${ }^{16}$

Años después, en 1793, Kant escribe La religión dentro de los límites de la mera razón, y alude de otra manera al pasaje: Adán y Eva son tentados por sus inclinaciones pero temen las consecuencias (la muerte); como decíamos atrás, antes de sucumbir a la tentación, Adán y Eva se guían por imperativos

${ }^{15} \mathrm{Cf}$. M. Lutero, op. cit., pp. 98-138.

16 Emmanuel Kant, "Comienzo presunto de la historia humana", en Filosofía de la Historia. Trad. de Eugenio Ímaz. México, FCE, 1979, pp. 70-73. 
hipotéticos. De aquí que la serpiente -que en realidad es una voz dentro de nosotros mismos, según Kant- mienta para minar la confianza en la autoridad de Dios: "no es seguro que mueran, al contrario, lo que sucederá es que se harán como dioses", al debilitar la amenaza del imperativo hipotético, la prohibición ya no tiene por qué acatarse. Muy distinto hubiera sido, sugiere Kant, si la prohibición se hubiera sustentado en un imperativo categórico. ${ }^{17}$ Pero justamente es un tipo de prohibición que no puede volverse categórica; adquirir el conocimiento del bien y el mal no es por sí un mal, sólo parece serlo porque es Dios quien lo prohíbe. Pero entonces volvemos al imperativo hipotético: "no hay que comer porque lo prohíbe Dios". Como decíamos atrás: antes de la caída, el ser humano parece capaz de actuar sólo guiado por imperativos hipotéticos: perseguir el placer o evitar el dolor; después de la caída, podrá orientarse por imperativos categóricos. Buber dice que con la desobediencia el hombre se hace consciente de la oposición entre lo que "es" y lo que "debería ser", y con ello se vuelve capaz de dar un sentido y un propósito a su existencia ${ }^{18}$ y tiene razón. Pero la caída, aun cuando sea una ganancia desde el punto de vista moral -y humano-, lleva consigo un castigo: la expulsión del paraíso, el advenimiento del sufrimiento y la muerte, la condena de sabernos mortales y querernos inmortales. La conciencia moral es también conciencia del dolor y la muerte, del espacio estrecho en el que se ubica esta recién adquirida autonomía. Esta es nuestra realidad, no es un paraíso, pero si usamos dicha capacidad, quizá podamos evitar que se convierta en un infierno. No por tener limitaciones y riesgos, la autonomía deja de ser ganancia. Aun quienes tienen todavia nostalgias religiosas y ven el episodio como la pérdida de la cercanía con Dios, habrán de reconocer la ventaja de que dicha cercanía, si ha de ser reconquis. tada, deberá plantearse en otros términos, que quizá no impliquen renunciar a una irrenunciable autonomía moral. Éste es el legado de Eva... ¿cómo no agradecerlo?

${ }^{17}$ E. Kant, La Religión dentro de los límites de la mera razón. Trad. de F. Fernández Marzoa. Madrid, Alianza Editorial, 1981, pp. 51-53, y J. Luis Bruch, La Philosophie Religieuse de Kant. Paris, Aubier Montaigne, 1968, pp. 73-74.

is Martin Buber, en N. Glatzer, ed., On the Bible. Nueva York, Schocken Books, 1982, pp. $19-21$. 